\title{
Business IT Alignment from Business Model to Enterprise Architecture
}

\author{
Boris Fritscher ${ }^{1}$ and Yves Pigneur \\ University of Lausanne, 1015 Lausanne, Switzerland, \\ boris.fritscher@unil.ch
}

\begin{abstract}
In this paper, we show how business model modelling can be connected to IT infrastructure, drawing parallels from enterprise architecture models such as ArchiMate. We then show how the proposed visualization based on enterprise architecture, with a strong focus on business model strategy, can help IT alignment, at both the business model and the IT infrastructure level.
\end{abstract}

Keywords: Business Model, IT Alignment, Enterprise Architecture, ArchiMate.

\section{Introduction}

Information Technology is becoming more and more ubiquitous, changing the way we exchange information and extending the realm of possibilities. This is true not only for Information Technology itself, but also for all domains interacting with it. Faster computation, increased storage and bandwidth, allow for new services, which in turn enable new business models, lower barrier of entry, more competition, but also possibilities for new innovation. The key, be it for the incumbent or the start-up, is to design and iterate around their business models. Furthermore, new services like cloud computing allow for experimenting with new business models without requiring huge investments in IT infrastructure. Nonetheless, a business model strategy still needs to be aligned with its processes and IT applications supporting them, regardless of the fact that IT infrastructure is virtual or physical.

As explained by Van Burren et al. [7] 'Enterprise architecture and business modeling methodologies meet in service offering and realization. In general, business models focus on the service value generated by a business, whereas enterprise architecture models show how a business realizes these services. Linking these approaches results in a powerful modeling tool that couples the value exchange between businesses and the costs that are required to realize these services'

Beyond the possibility to link cost, we want to provide a way to identify key activities and key resources supporting the business models, as well as highlight underutilized assets. This in turn helps in recognizing new business model opportunities. The identification of key components can be helped by matching the modelled business model and infrastructure to patterns of known combination of components. 
The objective of this paper is to propose a model construct that is similar to an enterprise architecture model, with the addition of a strong business model component, to allow for a better alignment of the value proposition with the IT infrastructure, which is require to realize this value.

\section{Frameworks}

In this section, we describe the different framework and models which individually address a part of the solution, before combining them into one model in the next section. The considered models are Enterprise Architecture frameworks, Business Models, as well as different classifications concerning IT Services.

\subsection{Enterprise Architecture}

Enterprise architecture describes components of an enterprise across domains and helps in communicating how they interact with each other. There are different frameworks supporting enterprise architecture such as The Zachman Framework [1], The Open Group Architecture Framework [8] and ArchiMate [3. The later separates the domains into three layers: Business, Application, and Technology. Each layer has sub-layers splitting the internal representation from the external, by exposing its services as interfaces to the upper layer. The top most business layer exposes the enterprise services to an additional layer containing external roles and actors.

As can be seen in figure 1, what makes ArchiMate particularly attractive, is its focus on having a visual representation, and the fact that it encourages the use of visual cues such as colours to highlight the different modelling layers 4. Moreover, ArchiMate also opts for one unique language (UML) to model every layer of the architecture, this eases the communication when teams responsible for the different layers need to collaborate.

Even thought, ArchiMate does go above the business processes layer and exposes external business services, there are still some limitations in order to be able to do a strategic analysis of the business model with only this framework. Furthermore, it is relevant to note that ArchiMate is infrastructure focused and has a bottom up construction. One model which can complement this lack in business model strategy is the Business Model Ontology presented in the next section.

\subsection{Business Model Ontology}

The Business Model Ontology is a representation of an enterprise's business model through nine building blocks. These elements were derived from an indepth literature review of a large number of previous conceptualizations of business models [5]. In this depiction, the business model of a company is a simplified 


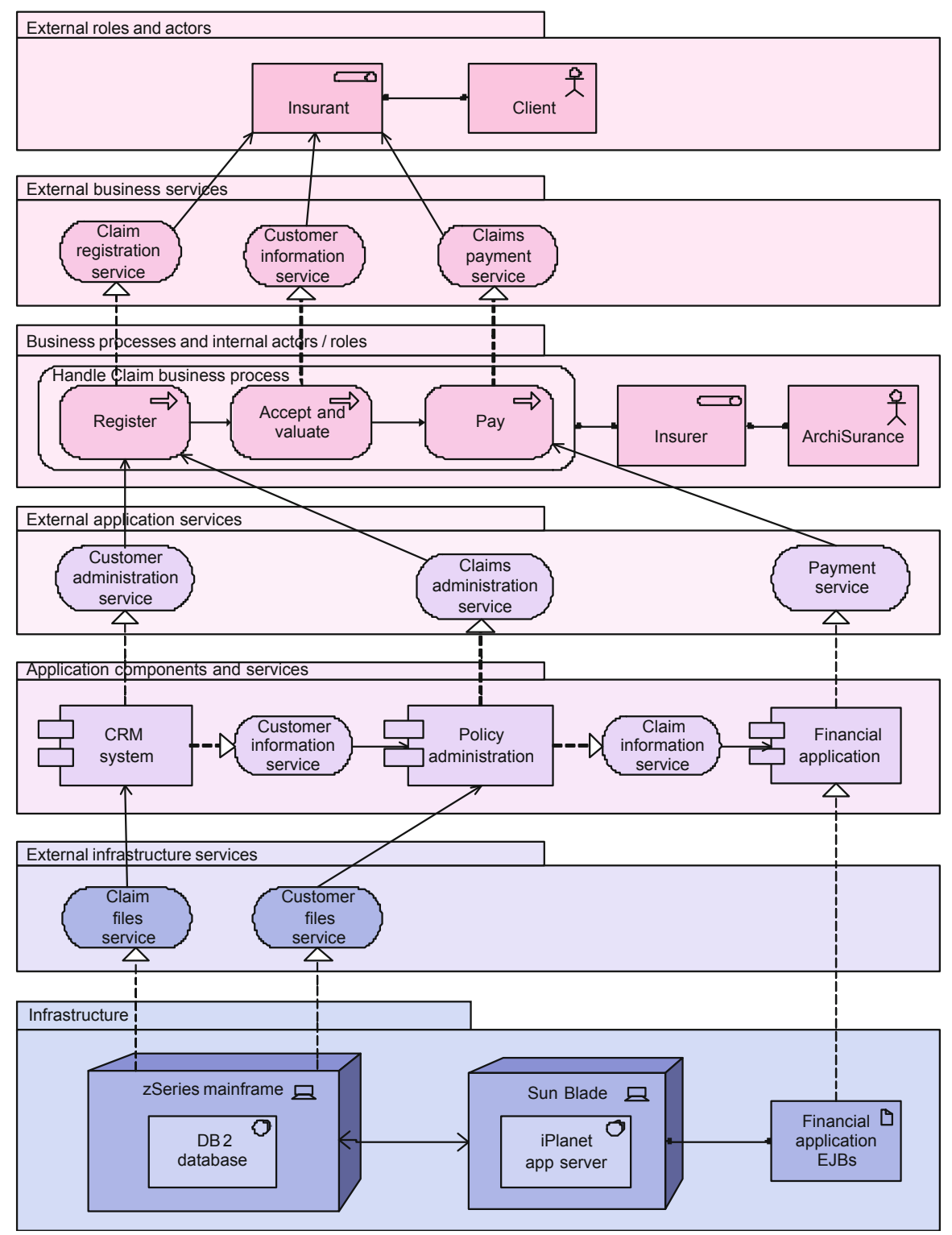

Fig. 1. Example of an ArchiMate model 


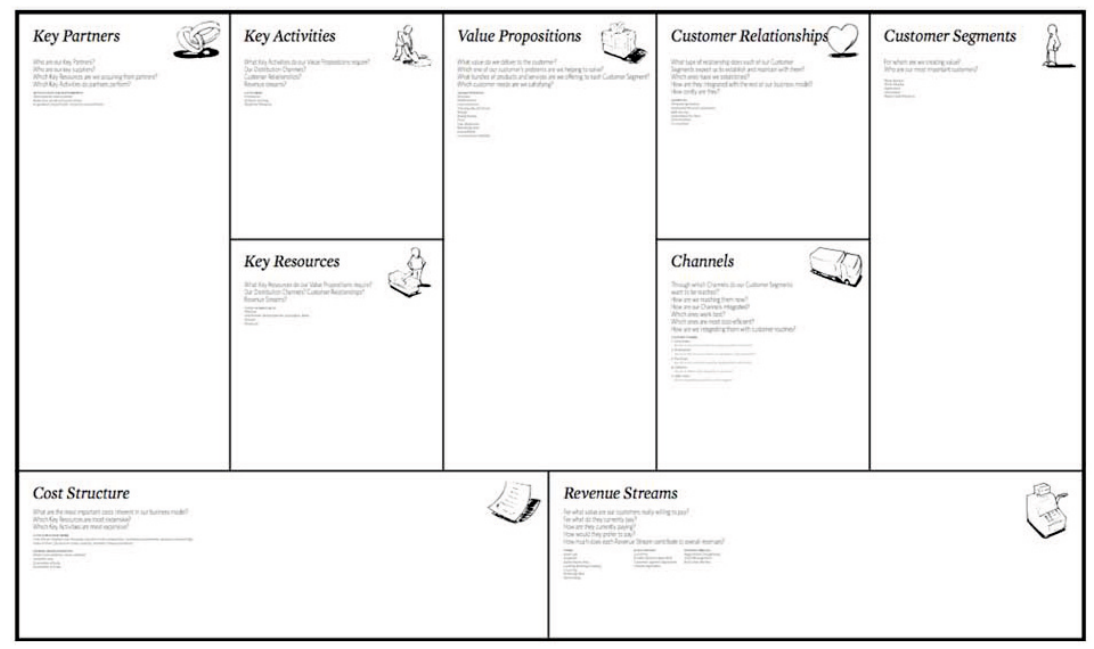

Fig. 2. Business Model Canvas

representation of its business logic viewed from a strategic standpoint (i.e. on top of Business Process Modeling), which can be seen in figure 2 .

At the center there is the Value Proposition, it describes which customer's problems are solved and why the offer is more valuable than similar products from competitors (product, service). The customer themselves are analyzed in Customer Segment, separated into groups to help in identifying their needs, desires and ambitions (singles, families). Distribution Channel illustrates how the customer wants to be reached and by whom he is addressed (Internet, store).

In addition, Customer Relationships specifies what type of relationship the customer expects and how it is establish and maintained with him (promotion, support, individual or mass). To be able to deliverer the value proposition the business has to have Resources (staff, machines, secret knowledge). And transform theses resources through Key Activities into the final product or service (development, production, secret process). Most of the time a business depends also, either for resources or for activities, on an external Partner Network (logistics, financial), which can provide better quality or a lower price on non essential components. As any business model would not be complete without financial information the last two building blocks focus on cost and revenue: The Cost Structure which should be aligned to the core ideas of the business model (key resources, key activities) and Revenue Streams which mirrors the value the customers are willing to pay and how they will perform the transaction (one time fee, subscription).

${ }^{1}$ http://businessmodelgeneration.com/downloads/business_model_canvas_poster.pdf 


\section{$2.3 \quad$ IT Services}

Approaching IT Services from a more managerial top down view, Weill et al.9. [10] have defined two useful classifications.

First from a management perspective they defined four objectives for an IT application portfolio: Infrastructure, Transactional, Informational and Strategic.

Second, in order to better describe and compare IT resources, Weill and Vitale 10] provide a classification of IT capabilities: Application Infrastructure, Communication, Data Management, IT Management, Security, Architecture \& Standards, Channel Management, IT Research \& Development, IT Education. This list is based on a comprehensive survey they did and each item has a set of sub-items helping in assessing the importance of the capability. The next section describes how theses models can be put together as a business visualization of an enterprise architecture.

\section{A Business Visualization of an Enterprise Architecture}

\subsection{Correspondence between Models}

A comparison of the elements of models and framework described in the previous section can be seen in figure 3 The main objective is to have a visualization with a similar structure as the enterprise architecture framework ArchiMate, but to provide additional business model considerations. The matching of elements has been done at a high level using the general definition given to them in each theory.

\subsection{Correspondence between BMO and ArchiMate}

In ArchiMate the top most layers' concern is with external actors, which in the case of the BMO, are its customers segments and partners. ArchiMate does not have a distinct layer for financial considerations like cost and revenue. Evidently, since BMO describes business models, most of its elements can be compared to ArchiMate's business layer. The activity element can be consider to be similar to the external application services which the application layer exposes to the business layer, but does certainly not go into detail on how the activities are produced. Some of key resources of ArchiMate's Technical layer might emerge in BMO's resource element, but in general it is too high level to really identify technical components.

BMO's buildings blocks can also be grouped in three more general perspectives: a financial perspective including cost and revenue, which cannot be found in ArchiMate; a customer perspective including value proposition, channels, relationship and customers, which can be compared to the higher sub-layers of ArchiMate's business layer; and an activity perspective including partners, resources and activities, which are close to the business process layer. 


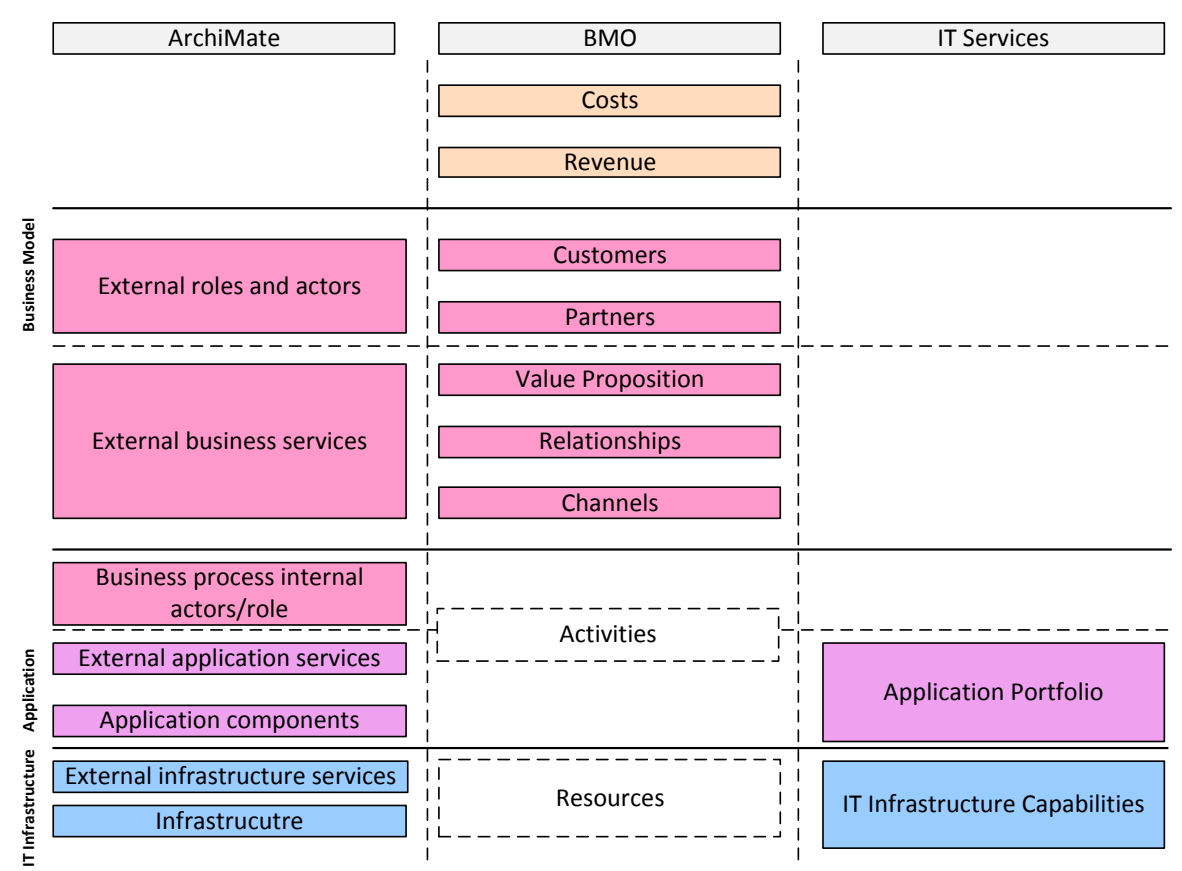

Fig. 3. Correspondence between ArchiMate's and models' elements

To complement the weak matching of BMO's activities and resources with the application and IT infrastructure layers, we propose to include the IT Services model in our construction.

\subsection{IT Services}

Instead of associating IT application directly to activities it is better to classify them by process type they support. One such classification is done in the internal perspective of Strategy Map[1]2]. Strategy Map is an evolution of the balanced scorecard from Kaplan-Norton, and provides an alternate, but very similar view to BMO's description of a business model. The four processes are Operations Management, Customer Management, Innovation and Regulatory \& Social. This classification should fill the gap where BMO's activities not fully match ArchiMate's business processes.

In addition, to better classify the IT infrastructure, instead of addressing it as common resources of the BMO, a more detailed classification can be used as presented in the IT Services framework. 

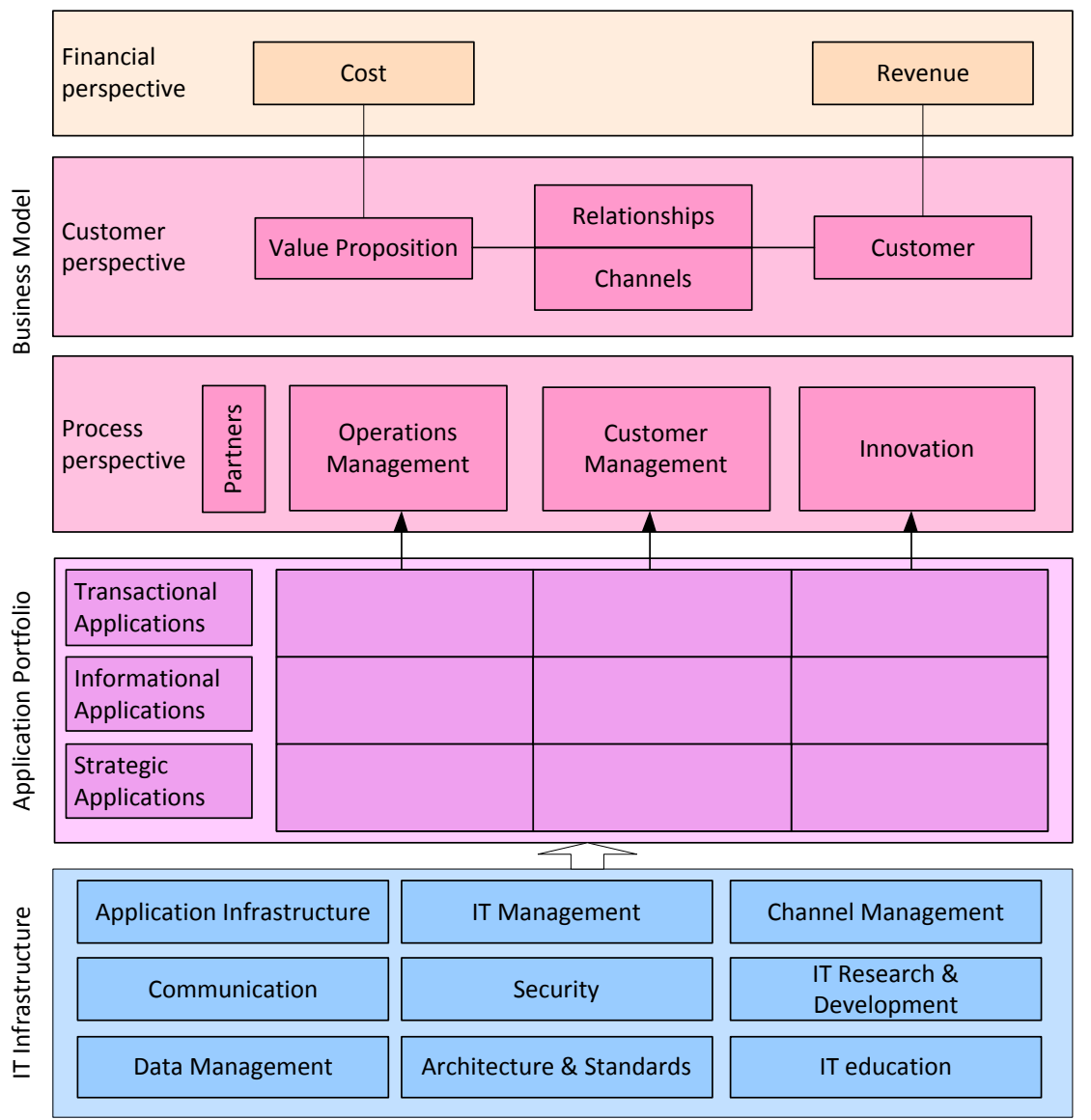

Fig. 4. Business visualization of an enterprise architecture inspired by [2] 3 [5] 10

\subsection{Visualization of the Connected Models}

Based on the described correspondence, figure 4 shows the proposed visualization integrating all the mentioned components. To further help connecting the components the IT services classification will be grouped into an application portfolio at the application level.

At the bottom, for the technology layer, the IT infrastructure is decomposed into the nine IT capabilities identified by Weill et al.[10]. Combination of these services enable different applications.

On the application layer, these applications make up the enterprise 'application portfolio. These can be organized into a three by three matrix: the rows of the portfolio distinguish transactional, informational and strategic applications; 
the columns are given by the processes the application support in the business layer.

The business layer has three sub layers: the process perspective which directly interfaces with the application layer, the customer perspective and the financial perspective, which represent the strategic business model.

The process perspective categorizes the process into three types: operations management, customer management and innovation.

In turn, these processes support different high level functions in the customer perspective layer.

The customer perspective can be detailed with the customer facing building block of BMO like Customer segments, through which channels they are reach and how the customer relationship is for each value proposition. In addition to the internal activities and resource which are described by the application and technical layers, there is also the need to identify partners involved in the realisation of some value propositions. The partners not being a customer, but deeply involved in the creation process of the value proposition, they are placed in the process perspective.

Finally, the financial layer takes into account the cost and revenue of the business model by basing itself on the functions used for each value proposition, which get their costs from the process they involve, which in turn can base their costs on the applications they involve, which themselves are based on IT services.

\section{Instantiation Case: Switcher SA}

The proposed visualization has been applied to illustrate the Business Model and Enterprise Architecture of a company called Switcher SA, which can be seen in figure 5. Switcher SA is a small private company engaged in the manufacture and distribution of garments with a particular focus on social responsibility throughout the whole value chain, from resource production to distribution of its products.

The way the diagram is structured, it is possible to see how the value proposition of responsibility produced garment (Ethics, Traceability) is delivered through the availability of tracing each step of the product. The traceability is made possible only by an innovative traceability management process, which heavily depends on a custom ERP application (Kookaburra), at the application portfolio level. To offer this application, at the IT Infrastructure level, there is a need for a custom ERP, which has to be developed in-house (IT research \& development). Additionally, the channel which allows the customers to to consult tracking information, is made possible by a special website (respectcode.org).

Since the proposed visualization is inspired by ArchiMate's structure, it can be compared to it (figure 6). This allows for an even better alignment of the business components and the IT infrastructure exposed by ArchiMate. 


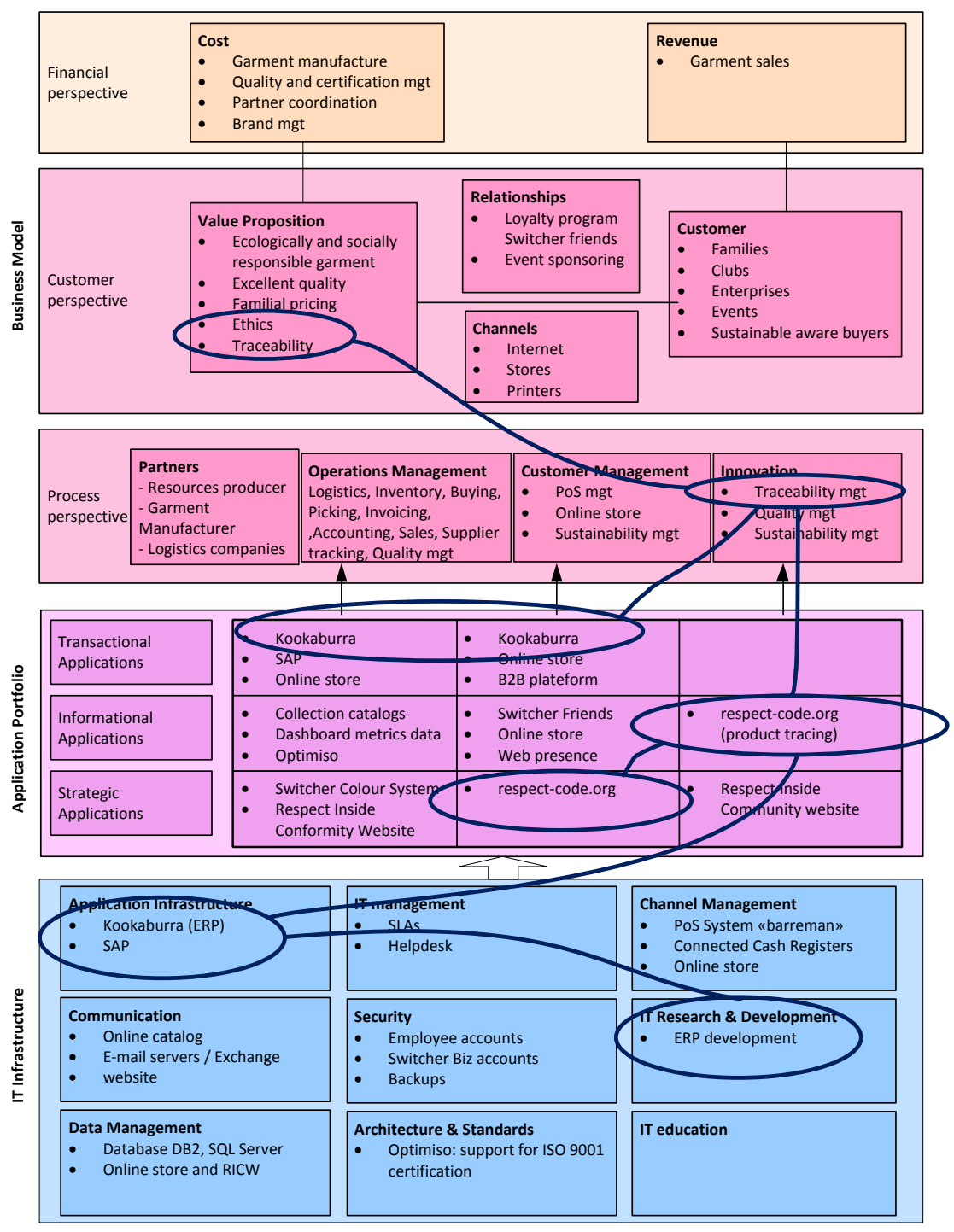

Fig. 5. Switcher SA Business Model Enterprise Architecture 


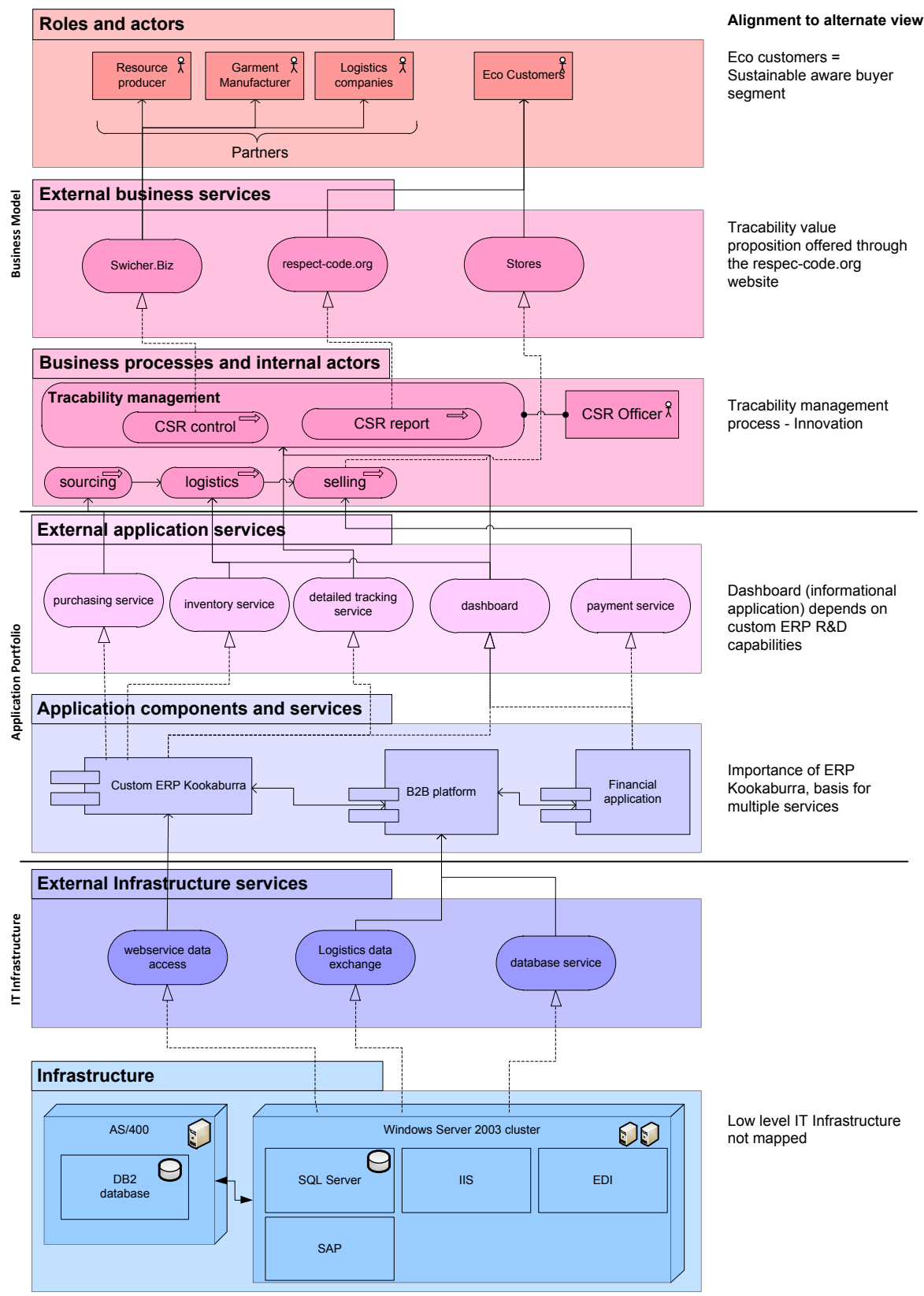

Fig. 6. Switcher SA ArchiMate for Tracability 


\section{Discussion and Future Works}

Comparing IT services and Business model and seeing how they are connected, helps in aligning them and highlighting the interactions they have. This opens the road to enable cost assignment to each offered value proposition. And also, it could allow prioritizing the importance of the assets to allow for strategic outsourcing of none core services, or providing new value propositions involving underutilized services.

The proposed visualization provides a more business oriented view on enterprise architecture and has a model for each level: business, application, and infrastructure. This provides alignment between the strategic business vision and the strategic information system considerations. In addition, since the construction is based on the structure of ArchiMate, which aligns the three layers, there is also the possibility to align the strategic with the operational. This enables not only the possibility to have both a top-down and a bottom-up view of the enterprise architecture, but also a business focused and an IT focused view, thereby helping the alignment of business strategy and technical IT infrastructure.

ArchiMate provides a more IT centric view with technical details that have to be abstracted in order to transform it into business visualization. And the business visualization elements have to be extended with additional information in order to build an ArchiMate model from it. Therefore one business visualization might result in the possibility of creating multiple variants of the corresponding ArchiMate model.

Further use cases have to be tested to see how the method can help in identifying misalignments, as well as a more systematic way to transition between both models.

\subsection{Applying Patterns}

Beyond the possibility to visualize the business model on a one page canvas, the $\mathrm{BMO}$ provides the ability to highlight and compare business model patterns 6 . A business model pattern describes some components of a business model and their relationships, in manner they can be applied to similar situation. As with patterns in other fields, this allows to identify missing components once a certain situation is recognized (freemium, double-sided, unbundling, long tail).

In addition, Weill et al. [10] also use the notion of pattern to classify the importance of the IT capabilities they defined for each situation. Therefore, there is the possibility to compare implication of patterns at the IT infrastructure level as well as the strategic business model level to further help with alignment.

For example, Switcher SA is playing the role of a value net integrator, which according to the IT capabilities pattern requires important channel management systems. This is the case for Switcher SA, which has an important investment in Point of Sale system, and does align to the business model strategy of owning stores to reach niche customers interested in responsibly produced garments. 


\subsection{External Factors}

In its current form, the proposed model focuses on the enterprises' internals. With the need for more collaboration and gaining importance of external factors, such as social and regulatory constraints, the model should be augmented with these concerns.

At the business layer, the environment map described for the BMO [6] could help in identifying external influences with its four components: key trends, market forces, industry forces and macro-economic forces. This in turn, as with the internal components, could be aligned to the fourth unused process category of strategy map: regulatory \& social processes. Alignment with the lower layers might be more difficult because these concerns seem to impact every component of the schema and cannot be resolved by just adding one more column.

Nonetheless, the proposed model already provides good insights for a large part of internal considerations and should be further tested in use cases and tried in practice.

\section{References}

1. Kaplan, R.S., Norton, D.P.: Linking the balanced scorecard to strategy. California Management Review 39(1) (1996)

2. Kaplan, R.S., Norton, D.P.: Strategy maps, vol. 2. Harvard Business School Press, Boston (2004)

3. Lankhorst, M.: Enterprise architecture modelling the issue of integration. Advanced Engineering Informatics 18(4), 205-216 (2004)

4. Lankhorst, M.: Enterprise architecture at work: Modelling, communication and analysis (2005)

5. Osterwalder, A., Pigneur, Y.: An e-business model ontology for modeling ebusiness. In: 15th Bled Electronic Commerce Conference, Bled, Slovenia, pp. 17-19 (2002)

6. Osterwalder, A., Pigneur, Y.: Business model generation: a handbook for visionaries, game changers, and challengers. Wiley, Hoboken (2010)

7. van Buuren, R., Gordijn, J., Janssen, W.: Business Case Modelling for E-Services. In: Proceedings of BLED 2005, vol. 8 (2005)

8. VHP. TOGAF Version 9 (TOGAF Series). VAN HAREN PUBLISHING, 2009.

9. Weill, P., Broadbent, M.: Leveraging the new infrastructure: how market leaders capitalize on information technology. Harvard Business Press, Boston (1998)

10. Weill, P., Vitale, M.: What IT infrastructure capabilities are needed to implement e-business models, vol. 1(1), pp. 17-34 (2002)

11. Zachman, J.A.: A framework for information systems architecture. IBM Syst. J. 26, 276-292 (1987) 